\title{
New Japanese Record of the Rare Cusk Eel Benthocometes australiensis (Actinopterygii: Ophidiiformes: Ophidiidae), a First Record of the Species from the Northern Hemisphere
}

\author{
Kaito Mizumachi ${ }^{1,2}$ and Hiromitsu Endo ${ }^{1}$ \\ ${ }^{1}$ Laboratory of Marine Biology, Faculty of Science and Technology, Kochi University, \\ 2-5-1 Akebono-cho, Kochi 780-8520, Japan \\ E-mail:bmbts1846@gmail.com \\ ${ }^{2}$ Corresponding author
}

(Received 19 September 2018; Accepted 16 November 2018)

\begin{abstract}
A specimen (114.4 mm SL) of the rare ophidiid species, Benthocometes australiensis Nielsen, 2010, was collected from a deep-sea water intake at a depth of $320 \mathrm{~m}$ off Cape Muroto, Kochi Prefecture, Shikoku Island, Japan. The species is previously only known from the holotype trawled off northwestern Australia. Thus, the present specimen is the first record from the Northern Hemisphere and the second record of the species. New Japanese names "Suisei-ashiro-zoku" and "Muroto-suisei-ashiro" are proposed for Benthocometes and B. australiensis respectively.
\end{abstract}

Key Words: Ophidiid fish, Kochi Prefecture, Japan, deep-sea water intake, range extension.

\section{Introduction}

The ophidiid genus Benthocometes Goode and Bean, 1896 includes two valid species, Benthocometes robustus (Goode and Bean, 1886) and Benthocometes australiensis Nielsen, 2010. The former is considered to be a senior synonym of Benthocometes armatus (Döderlein, 1886) and Benthocometes muraenolepis (Vaillant, 1888) (Bougis and Ruivo 1954; Nielsen 2010). Benthocometes robustus is known from off New Jersey, the United States of America, to Rio Grande do Sul, Brazil, along the Atlantic coasts of the Americas, including the Gulf of Mexico and Caribbean Sea (Haimovici et al. 1994; Nielsen 2010), and in the eastern Atlantic from off northwestern Africa and several localities in the Mediterranean Sea from off Spain to Cyprus (Nielsen 2010). Benthocometes australiensis is known only from the holotype from off northwestern Australia (Nielsen 2010).

In 2006, a single specimen of Benthocometes was collected from a deep-sea water intake operated by Kochi Prefectural Deep Seawater Laboratory, Shikoku Island, Japan, at a depth of $320 \mathrm{~m}$ off the eastern side of Cape Muroto. This specimen was identified as B. australiensis based on the circular form of its palatine dentition, and a combination of meristic and morphometric characters. Thus, we report the first record of B. australiensis from the Northern Hemisphere, and provide an updated diagnosis and a description of the Japanese specimen.

\section{Materials and methods}

Methods for measurements and counts follow Nielsen et al. (1999). Standard and head lengths are abbreviated as SL and HL, respectively. Vertebrae and vertical-fin rays were counted from $\mathrm{x}$-ray radiograph. Institutional codes follow Fricke and Eschmeyer (2018). The present specimen is deposited in the Laboratory of Marine Biology, Faculty of Science and Technology, Kochi University (BSKU).

Benthocometes Goode and Bean, 1896

[New Japanese name: Suisei-ashiro-zoku]

Benthocometes australiensis Nielsen, 2010

[New standard Japanese name: Muroto-suisei-ashiro]

(Figs 1, 2; Table 1)

Benthocometes australiensis Nielsen, 2010: 59 (original description; holotype: NMV A 29728-016; type locality: off northwestern Australia, 390-394 m depth).

Material examined. BSKU 117791, $114.4 \mathrm{~mm} \mathrm{SL}$, $33^{\circ} 17^{\prime} 38.0^{\prime \prime} \mathrm{N}, 134^{\circ} 13^{\prime} 34.3^{\prime \prime} \mathrm{E}$, off eastern side of Cape Muroto, Kochi Prefecture, Shikoku Island, Japan, $320 \mathrm{~m}$ depth, pumped up together with deep seawater, collected by Kochi Prefectural Deep Seawater Laboratory, 4 April 2006.

Diagnosis. Long gill rakers on anterior arch 3; predorsal pterygiophores 4 ; teeth patch on palatine circular; predorsal length $17.7-22.0 \%$ of SL; upper jaw length $8.0-8.7 \%$ of SL; dorsal-fin origin above 3rd vertebra; anal-fin origin below bases of 24th-28th dorsal-fin rays; all teeth on jaws conical, canine-like; distinct supraorbital pores [Modified from 


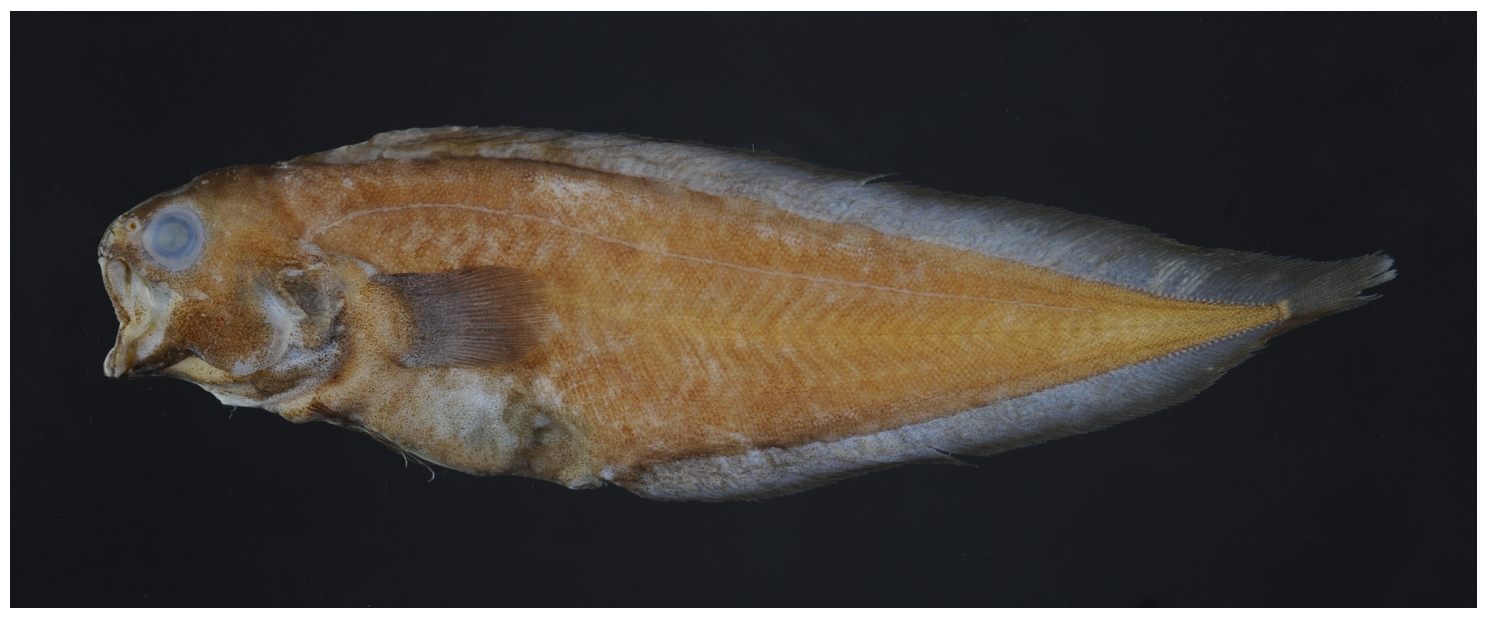

Fig. 1. Benthocometes australiensis, BSKU 117791, $114.4 \mathrm{~mm}$ SL. Preserved condition.

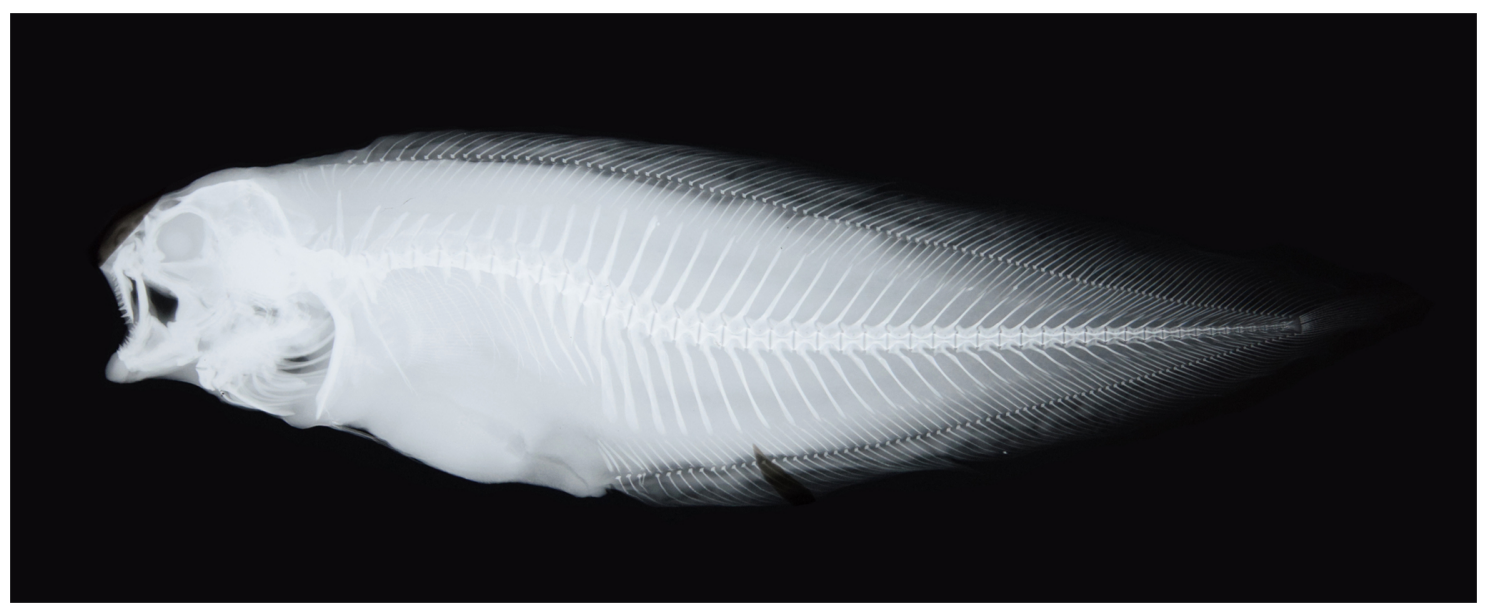

Fig. 2. Soft x-ray image of Benthocometes australiensis, BSKU 117791, $114.4 \mathrm{~mm}$ SL.

\section{Nielsen (2010)].}

Description of Japanese specimen. Selected counts and measurements are given in Table 1. Body short, compressed, robust. Head relatively small, its length $47.8 \%$ of preanal length. Head and body fully covered with small scales (size of each scale under pectoral fin about $1.7 \mathrm{~mm}$ in diameter). Lateral line distinct and short, ending a head-length from caudal-fin base, its length $65.6 \%$ of SL. Snout short, its length $23.1 \%$ of HL. Eyes relatively large, diameter $24.7 \%$ of HL. Mouth small, posterior end of maxilla below middle of eye. Anterior nostril with short tube. Posterior nostril larger than anterior, without tube, adjoining eye. Tip of snout with about 20 small, black skin flaps. Opercle with 2 strong and sharp spines. Origin of dorsal fin anterior to a vertical from pectoral-fin base. Anal-fin origin slightly anterior to horizontal mid-point of body, located below 14th vertebra. Pelvic fin originating below dorsal-fin origin, its tip below middle of pectoral fin. Caudal fin connected with dorsal and anal fins. Fin membrane of vertical and pectoral fins thin. Anterior gill arch with 2-3 small, spiny knobs on upper branch; lower branch with 3 long rakers and 7 small, spiny knobs. Cephalic sensory canals with open pores; number of pores in supraorbital row 3 , infraorbital row 5 , mandib- ular row 3 and preopercular row 2. All conical teeth small, canine-like, curved. Vomerine tooth patch small, circular, with 12 teeth. Palatine tooth patch short, oval, with about 20 teeth. Teeth on premaxilla with 2 rows near symphysis, 1 row posteriorly. Teeth on lower jaw with 2-3 rows near symphysis, 1 row posteriorly.

Axial skeleton (based on radiographs; Fig. 2). First neural spine short, half length of second spine. 1st-7th precaudal vertebrae with pointed neural spines. 8th-12th precaudal vertebrae with relatively blunt neural spines and all caudal neural spines with pointed tips. Haemal spines of precaudal vertebrae with pointed tips. Neural spines on precaudal vertebrae, 5th-12th with enlarged bases. Parapophyses on 6th-12th vertebrae increasing in width and length toward 12th one. Pleural ribs on 3rd-12th vertebrae. First predorsal pterygiophores above 1st vertebra.

Color in alcohol (Fig. 1). Ground color of head and body brown with numerous small black spots on head, pectoral fin and abdomen. Fin membrane of vertical and pectoral fins translucent. Vertical fins with numerous small brown spots. Lower jaw relatively pale, around symphysis blackish. Inside of operculum densely covered with melanophores. Lateral line pale. 
Table 1. Measurements and counts of Benthocometes australiensis and B. robustus.

\begin{tabular}{|c|c|c|c|}
\hline & \multirow{2}{*}{$\begin{array}{l}\text { This study } \\
\text { B. australiensis } \\
\text { BSKU } 117791\end{array}$} & \multicolumn{2}{|c|}{ Nielsen (2010) } \\
\hline & & $\begin{array}{l}\text { B. australiensis } \\
\text { Holotype }\end{array}$ & $\begin{array}{c}\text { B. robustus } \\
29 \text { specimens }\end{array}$ \\
\hline $\mathrm{SL}(\mathrm{mm})$ & 114.4 & 93 & $20-123$ \\
\hline \multicolumn{4}{|l|}{ Counts } \\
\hline Dorsal-fin rays & 98 & 98 & $93-111$ \\
\hline Predorsal pterygiophores & 4 & 4 & $7-10$ \\
\hline Caudal-fin rays & 11 & 11 & 11 \\
\hline Anal-fin rays & 77 & 80 & $78-94$ \\
\hline Pectoral-fin rays & 28 & 30 & $28-32$ \\
\hline Pelvic-fin rays & 2 & 2 & 2 \\
\hline Precaudal vertebrae & 12 & 12 & $11-12$ \\
\hline Total vertebrae & 49 & 50 & $47-50$ \\
\hline Dorsal-fin origin above vertebra no. & 3 & 3 & $6-7$ \\
\hline Anal-fin origin below dorsal-fin ray no. & 28 & 24 & $17-20$ \\
\hline Anal-fin origin below vertebra no. & 14 & 15 & $13-16$ \\
\hline Long gill rakers & 3 & 3 & $9-12$ \\
\hline Pseudobranchial filaments & 7 & $7-8$ & $6-8$ \\
\hline \multicolumn{4}{|l|}{ Measurements } \\
\hline \multicolumn{4}{|l|}{$\%$ of SL } \\
\hline Head length & 21.8 & 23.0 & $20.0-25.0$ \\
\hline Depth at anal-fin origin & 25.6 & 22.5 & $17.0-21.5$ \\
\hline Upper-jaw length & 8.0 & 8.7 & $11.0-13.0$ \\
\hline Diameter of eye window & 5.4 & 5.7 & $5.4-6.9$ \\
\hline Interorbital width & 5.8 & 5.1 & $5.1-6.4$ \\
\hline Postorbital length & 13.1 & 13.0 & $10.5-13.0$ \\
\hline Preanal length & 45.6 & 46.0 & $40.5-47.0$ \\
\hline Predorsal length & 17.7 & 22.0 & $26.5-31.0$ \\
\hline From base of pelvic to anal-fin origin & 23.9 & 25.0 & $22.0-27.5$ \\
\hline Pectoral-fin length & 15.2 & 14.0 & $9.5-13.0$ \\
\hline Pelvic-fin length & 11.0 & 14.0 & $9.1-12.5$ \\
\hline Snout to post. end of lateral line & 82.5 & 79.0 & $74-86$ \\
\hline
\end{tabular}

Distribution. Known from the southeastern Indian Ocean off northwestern Australia (type locality; Nielsen 2010) and the northwestern Pacific off southwestern Japan (this study), at depths of 320-394 m.

Remarks. The Japanese specimen identified as a species of Benthocometes is clearly distinguished from other ophidiid genera by the following combination of characters: 2 posteriorly directed opercle spines, 3 long gill rakers, 7 pseudobranchial filaments, 4 predorsal pterygiophores, a blunt snout, and diameter of eye larger than snout length (Nielsen et al. 1999; Nielsen 2010; this study). Nielsen (2010) reported that the two valid species of Benthocometes, B. robustus and B. australiensis, can be distinguished from each other by the numbers of long gill rakers on the anterior arch (3 in $B$. australiensis vs. 9-12 in B. robustus) and predorsal pterygiophores (4 vs. 7-10), form of palatine dentition (circular $v s$. elongate), predorsal length ( $22.0 \%$ vs. $26.5-31.0 \% \mathrm{SL})$, upper jaw length ( $8.7 \%$ vs. $11.0-13.0 \%$ SL), position of dorsal-fin origin (above 3 rd vs. 6 th-7th vertebrae), position of anal-fin origin (below 24th vs. 17th-20th dorsal-fin rays), form of teeth (large canine-like teeth $v s$. small granular teeth), and supraorbital pores (developed vs. undeveloped). These characters of the Japanese specimen agree well with those of $B$. australiensis given by Nielsen (2010) except the position of the anal-fin origin, which is located below the base of 28th dorsal-fin ray in the Japanese specimen but below the base of 24th dorsal-fin ray in the holotype. According to Nielsen (2010), this character's interspecific range in B. robustus is four, and we therefore regard this slight difference in the position of the anal-fin origin (below bases of 24th-28th dorsal-fin rays) as intraspecific variation.

Benthocometes australiensis was described by Nielsen (2010) based on the $93 \mathrm{~mm}$ SL holotype collected from off northwestern Australia. The Japanese specimen is the second record of B. australiensis, and the first record from the Northern Hemisphere. In addition, based on the specimen BSKU 117791, the new standard Japanese names, "Suiseiashiro-zoku" and "Muroto-suisei-ashiro," are proposed for the genus and species, respectively. These names are derived from part of the generic name, "comet" (=Suisei), the Japanese name for ophidiids (=Ashiro), and the locality of the Japanese specimen (=Muroto).

\section{Acknowledgments}

We thank Y. Ogita, Y. Abe and K. Inoue (Kochi Prefectural Deep Seawater Laboratory) for collecting and donating 
the present specimen. G. Yearsley (Hobart, Australia) kindly edited the English text.

\section{References}

Bougis, P. and Ruivo, M. 1954. Recherches sur le poisson de profundeur Benthocometes robustus (Goode et Bean) (=Pteridium armatum, Doederlein) (Brotulidae). Vie et Milieu, Supplement 3: 155-209.

Fricke, R. and Eschmeyer, W. N. 2018. A guide to fish collection in the Catalog of Fishes. Available at http://researcharchive.calacademy. org/research/ichthyology/cataloc/collections.asp (12 April 2018).

Goode, G. B. and Bean, T. H. 1896. Oceanic ichthyology, a treatise on the deep-sea and pelagic fishes of the world, based chiefly upon the collections made by the steamers Blake, Albatross, and Fish
Hawk in the northwestern Atlantic, with an atlas containing 417 figures. Special Bulletin United States National Museum 2: 1-553.

Haimovici, M., Martins, A. S., Figueiredo, J. L., and Vieira, P. C. 1994. Demersal bony fish of the outer shelf and upper slope off southern Brazil subtropical convergence ecosystem. Marine Ecology Progress Series 108: 59-77.

Nielsen, J. G. 2010. Revision of the bathyal fish genus Benthocometes (Teleostei: Ophidiidae) with a new species from off NW Australia. Zootaxa 2561: 59-68.

Nielsen, J. G., Cohen, D. M., Markle, D. F., and Robins, C. R. 1999. FAO Species Catalogue, Volume. 18. Ophidiiform Fishes of the World (Order Ophidiiformes). An Annotated and Illustrated Catalogue of Pearlfishes, Cuskeels, Brotulas and Other Ophidiiform Fishes Known to Date. FAO Fisheries Synopsis No. 125 (18). FAO, Rome, $178 \mathrm{pp}$. 